\title{
Author Correction: Estrogen-related receptor gamma functions as a tumor suppressor in gastric cancer
}

\author{
Myoung-Hee Kang (10) 1,2,3, Hyunji Choi ${ }^{4}$, Masanobu Oshima ${ }^{5}$, Jae-Ho Cheong ${ }^{6}$, Seokho Kim7, Jung Hoon Lee (1) ${ }^{8}$, \\ Young Soo Park ${ }^{9}$, Hueng-Sik Choi ${ }^{10}$, Mi-Na Kweon ${ }^{2}$, Chan-Gi Pack ${ }^{1,2}$, Ju-Seog Lee (1) ${ }^{3}$, Gordon B. Mills ${ }^{3}$, \\ Seung-Jae Myung ${ }^{1,2,8} \&$ Yun-Yong Park ${ }^{1,2}$
}

Correction to: Nature Communications; https://doi.org/10.1038/s41467-018-04244-2; published online 15 May 2018

The original version of this Article contained errors in Figs. 4, 5, and 6. In Fig. 4d, the $x$-axis label incorrectly read 'blank, +, blank, +', and in Fig. 5e, the bars of the second graph from the left were coloured blue-orange-blue-orange. Both of these errors have been fixed in the PDF and HTML versions of the Article. Furthermore, in Fig. 6a, the right-hand image of AGS cells treated with $5 \mu$ M DY131 was inadvertently replaced with a duplicate of the left-hand image. The correct version of this figure panel appears below. For transparency, the error has not been corrected in the PDF or HTML versions of the Article.

Published online: 31 August 2018

Open Access This article is licensed under a Creative Commons Attribution 4.0 International License, which permits use, sharing, adaptation, distribution and reproduction in any medium or format, as long as you give appropriate credit to the original author(s) and the source, provide a link to the Creative Commons license, and indicate if changes were made. The images or other third party material in this article are included in the article's Creative Commons license, unless indicated otherwise in a credit line to the material. If material is not included in the article's Creative Commons license and your intended use is not permitted by statutory regulation or exceeds the permitted use, you will need to obtain permission directly from the copyright holder. To view a copy of this license, visit http://creativecommons.org/licenses/by/4.0/.

() The Author(s) 2018

\footnotetext{
${ }^{1}$ ASAN Institute for Life Sciences, ASAN Medical Center, University of Ulsan College of Medicine, Seoul 05505, Republic of Korea. ${ }^{2}$ Department of Convergence Medicine, University of Ulsan College of Medicine, Seoul 05505, Republic of Korea. ${ }^{3}$ Department of Systems Biology, MD Anderson Cancer Center, Houston, TX 77030, USA. ${ }^{4}$ Department of Biological Sciences, Dong-A University, Busan 49315, Republic of Korea. ${ }^{5}$ Division of Genetics, Cancer Research Institute, Kanazawa University, Kanazawa 920-8641, Japan. ${ }^{6}$ Department of Surgery, Yonsei University College of Medicine, Seoul 03722, Republic of Korea. ${ }^{7}$ Aging Research Institute, Korea Research Institute of Bioscience and Biotechnology, Daejeon 34141, Republic of Korea. ${ }^{8}$ Department of Gastroenterology, University of Ulsan College of Medicine, Seoul 05505, Republic of Korea. ${ }^{9}$ Department of Pathology, University of Ulsan College of Medicine, Seoul 05505, Republic of Korea. ${ }^{10}$ National Creative Research Initiatives Center for Nuclear Receptor Signals and Hormone Research Center, School of Biological Sciences and Technology, Chonnam National University, Gwangju 61186, Republic of Korea. Correspondence and requests for materials should be addressed to S.-J.M. (email: sjmyung@amc.seoul.kr) or to Y.-Y.P. (email: yypark@amc.seoul.kr)
} 


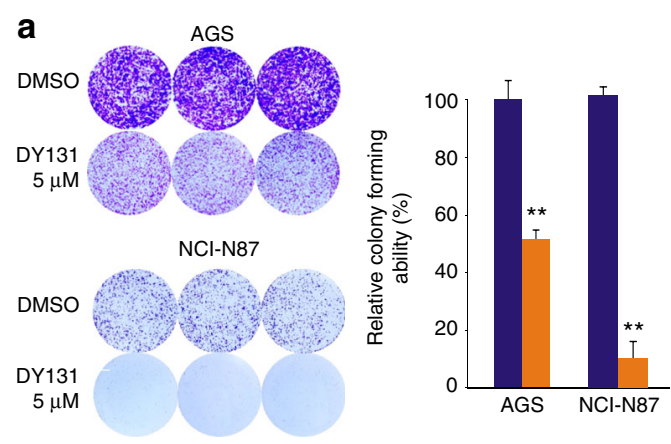

b

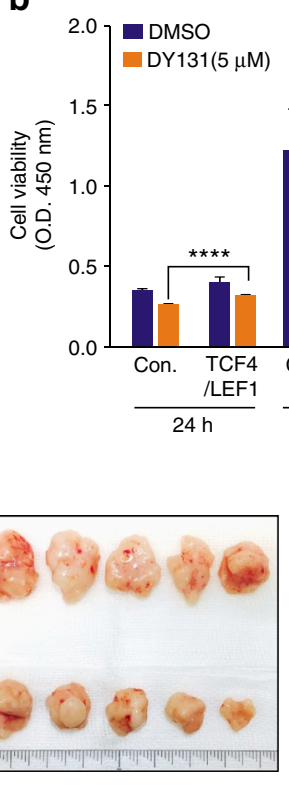

C

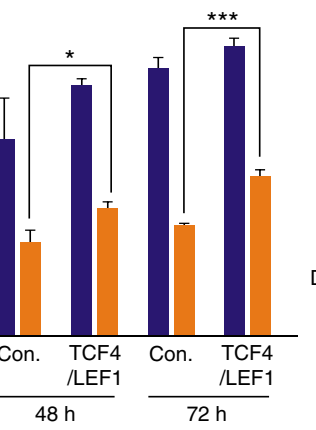

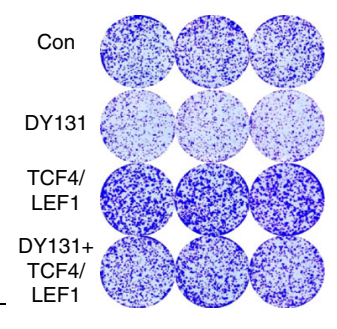

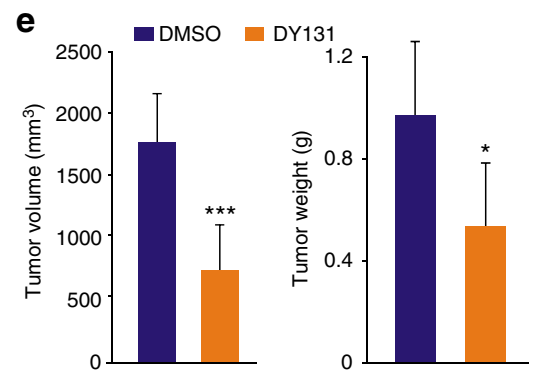

$\mathbf{f}$
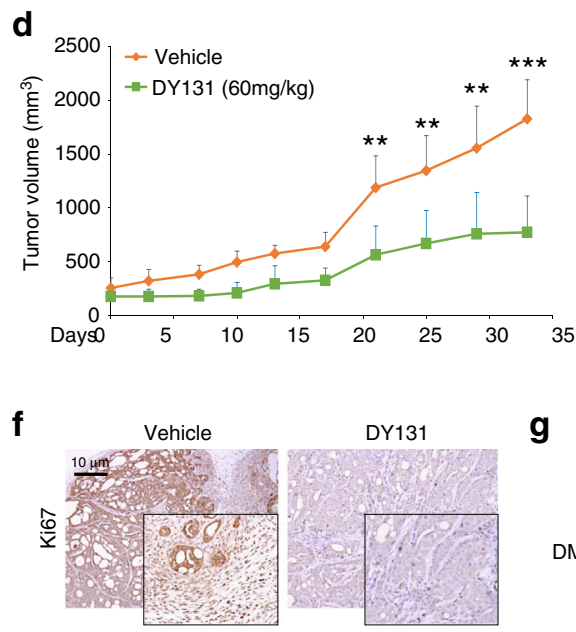

g

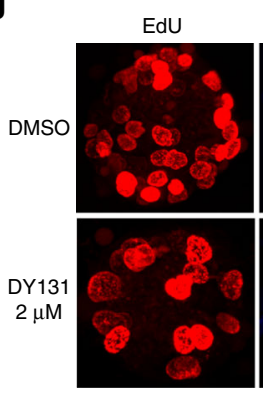

Hoechst

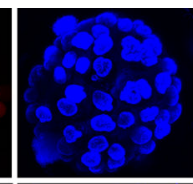

Merge

h
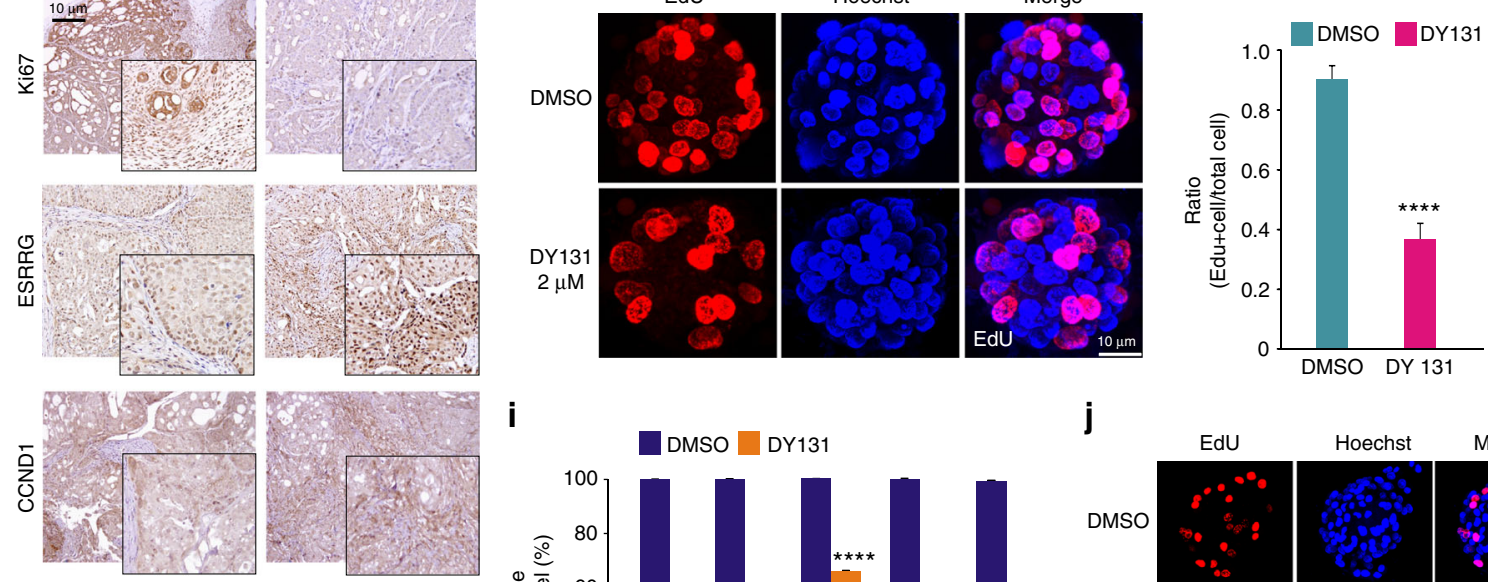

i

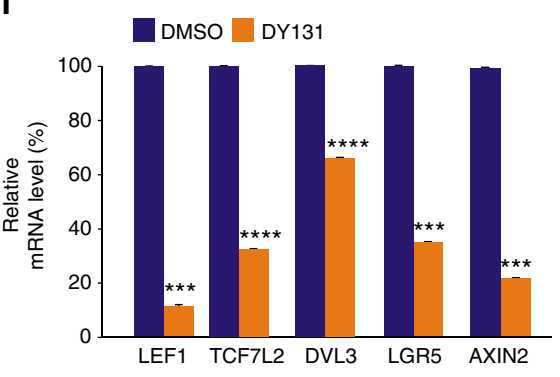

j $\quad$ EdU

Hoechst

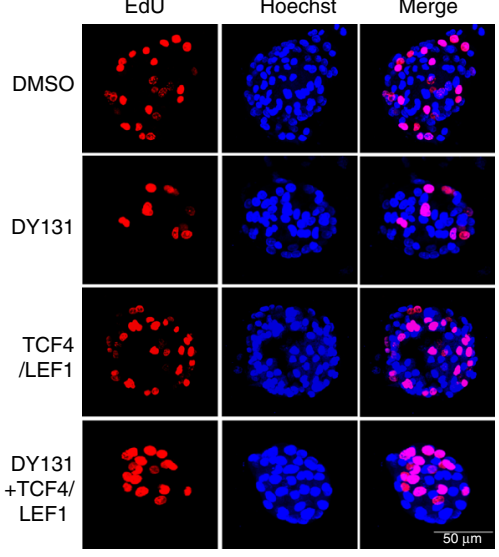

$\mathbf{k}$

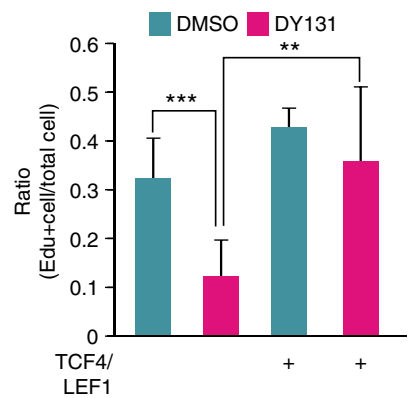

Fig. 6 